\title{
EDITORIAL
}

\section{In memoriam: Herbert Benzer}

\author{
Walter R Hasibeder' and Norbert J Mutz ${ }^{* 2}$
}

One of the most celebrated public figures in anesthesiology and critical care medicine in Austria, Herbert Benzer (Figure 1), died on the 1st of May 2011. We, his former students, are left with great sadness.

Herbert Benzer was an outstanding person. Having finished his academic study of medicine, he first completed a residency in surgery at the University of Vienna. After an accident, he had to switch his specialty training and became a consultant in anesthesiology and critical care medicine. Early in his training, he became captivated by respiratory physiology, pathophysiology, and the management of respiratory failure. His special interest was surfactant alteration during artificial ventilation. In later years, he was a leader in the development of new therapeutic strategies for the prevention and treatment of acute respiratory distress syndrome. Decades ago, he taught us the importance of the selection of an adequate positive end-expiratory pressure and an upper pressure limit to avoid mechanical damage to the already-injured lung. At that time, he was already emphasizing the importance of intermittent spontaneous breathing to improve respiratory gas exchange and to avoid or attenuate the development of atelectasis in dependent lung areas.

Owing to his outstanding reputation, he became head of the Department of Anesthesiology and General Critical Care Medicine at the University Hospital of the Leopold-Franzens University of Innsbruck in 1985. Under his leadership, clinical practice and scientific activities shared equal prominence. These developments could happen only because of the particular personality of Herbert Benzer. He was a warm-hearted, inspiring, and motivating leader. His office was always open to everyone. His fatherly character presented itself most notably during conversations, when he was, for example, offering solutions to a problem or providing encouragement.

As a clinician, Herbert Benzer made every effort to decrease suffering and to restore health to his patients.

\footnotetext{
*Correspondence: norbert.mutz@i-med.ac.at

2Department of General and Surgical Intensive Care Medicine, Medical University Innsbruck, Anichstrasse 35, 6020 Innsbruck, Austria

Full list of author information is available at the end of the article
}

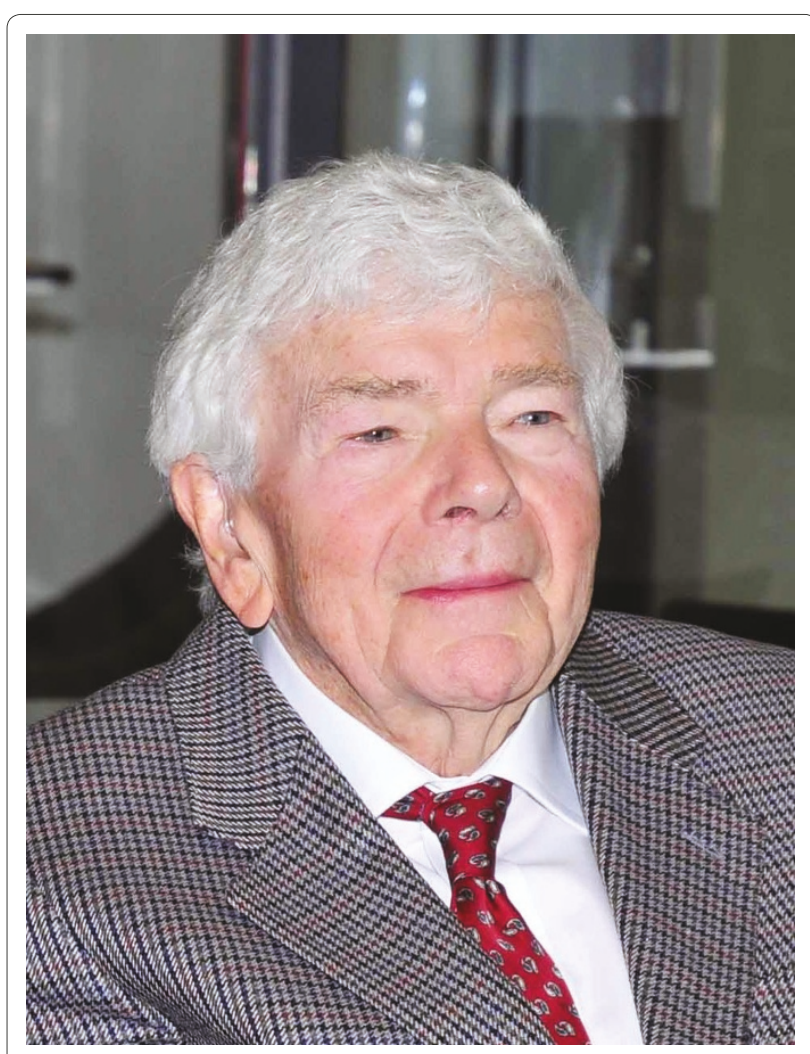

Figure 1. Herbert Benzer.

As a teacher, he showed that intensive care medicine is not only a technical art but also a medical discipline with tremendous responsibility to respect the dignity of patients.

We, his former residents, owe him so much. We will never forget him.

\section{Author details}

'Department of Anesthesiology, Intensive Care and Palliative Care Medicine, Hospital of the Barmherzigen Schwestern, Schlossberg 1,4910 Ried im Innkreis, Austria. ${ }^{2}$ Department of General and Surgical Intensive Care Medicine, Medical University Innsbruck, Anichstrasse 35, 6020 Innsbruck, Austria.

Published: 13 June 2011

doi:10.1186/cc10238

Cite this article as: Hasibeder WR, Mutz NJ: In memoriam: Herbert Benzer. Critical Care 2011, 15:165. 